\title{
Some Useful Sources on Harm, Abuse, Agency and Resilience Across the Lifespan
}

\author{
Alison Dawson \\ Department of Applied Social Science, University of Stirling \\ E-mail: a.s.f.dawson@stir.ac.uk
}

The URL addresses listed here access websites holding an array of electronic resources relevant to the understanding of harm, abuse, agency and resilience across the lifespan. Many websites include links to additional reports, research papers, reviews and other sources of information. Due to the breadth of subject area and limitations on available space, the websites should be regarded as an indicative sample rather than an exhaustive list of relevant information currently available on the internet. Only English language sites have been included. All website addresses were available on 31 July 2009.

\section{Interrogating harm and abuse - academic research centres, focused resource collections}

http://www.cats-rp.org.uk/

Website of the Centre for Abuse and Trauma Studies (CATS), launched in March 2009 and administered jointly by Royal Holloway, University of London and Kingston University, London. The Centre aims to further the understanding, treatment and policy implications of abuse and trauma and its consequences. The webpage provides links to current projects, partner organisations, and training and CPD. Research topics include: experience of physical abuse/domestic violence; psychological abuse and sexual abuse/sexual assaults in children, adolescents and adults. References are provided to recent publications, primarily in the area of childhood abuse.

http://www.cwasu.org/default.asp?pageid=HOME\&pagekey $=1$

Website of the Child and Woman Abuse Studies Unit (CWASU) at London Metropolitan University. Founded in 1987, CWASU employs feminist research practices to conduct research and provide training relating to gender violence and child abuse. The website provides access to a wide variety of resources, including: papers and publications, many of which are available to download in pdf format; statistics and information on selected topics, including links to further information; and information on and links to campaigning groups and other organisations relevant to the field of violence against women and children.

http://www.bristol.ac.uk/sps/research/centres/vawrg

Website of the Violence Against Women Research Group (VAWRG) at the University of Bristol. Founded in 1990 as the Domestic Violence Research Group (DVRG), the 
VAWRG has a long history of feminist research on violence against women and feeding this into policy and practice nationally, internationally and at a local level. The Group regularly runs research-based conferences aimed at academics and practitioners, details of which are made available via the website. The site also provides links to reports from the VAWRG's research, which are available to download in pdf format.

http://www.ncea.aoa.gov/ncearoot/Main_Site/index.aspx

Website of the National Centre on Elder Abuse (NCEA), directed by the United States' Administration on Aging. According to its website, the NCEA, established in 1988, is 'a national resource center dedicated to the prevention of elder mistreatment'. In addition to making a range of resources available on-line, the NCEA collaborates on research; provides training; and provides expertise on policy developments and initiatives around elder abuse, neglect and exploitation.

http://www.cane.udel.edu/index.asp

Home page for the Clearinghouse on Abuse and Neglect of the Elderly (CANE), a searchable online database of more than 6,000 published items on the abuse and neglect, self-neglect and financial exploitation of elders operated by the University of Delaware, USA. Materials referenced include: journal articles, books, reports, hearing transcripts, videos, memoranda of understanding (MOU) and online resources. The database provides citation information and brief summaries for each item and, in limited instances, an electronic link to the source. The CANE website also provides links to a series of subjectspecific bibliographies and to other online providers of resources providing information about issues relevant to vulnerable adults.

http://www.austdvclearinghouse.unsw.edu.au/

Website of the Australian Domestic and Family Violence Clearinghouse, a national organisation providing information about family and domestic violence issues and practice funded by the Australian Government and linked to the Centre for GenderRelated Violence Studies, University of New South Wales. The website provides access to three searchable databases: a database of research and resources around family and domestic violence, a good practice database and a database of researchers on issues around domestic and family violence. Each database also provides a browsable list of subject areas. Database entries provide: citation data, abstracts/summaries, data on the materials type and links to sources.

http://www.alcoholinfo.nsw.gov.au/preventing_abuse_and_harm/drink_spiking

This is a section of the Alcoholinfo website, the official New South Wales Government of Australia's website on alcohol issues. The Alcohollnfo site outlines policies on alcohol, including the responsible supply and consumption of alcohol, alcohol advertising and the role of parents, families, industry and the broader community in reducing alcohol abuse. This section provides links to information on drink spiking, date rape and drug assisted sexual assault (DASA) from a range of international sources. 


\section{Enabling agency and resilience - resources around raising awareness and supporting survivors}

http://www.elderabuse.org.uk/index.htm

The UK charity 'Action on Elder Abuse' (AEA) participates in and organises events and activities that raise awareness and stimulate debate on the subject of elder abuse. They also operate helplines that provide advice and guidance to older people and others; provide training packages and programmes on best practice to care staff and others; and are involved in a range of projects related to elder abuse. The site includes access to a variety of resources under 'Useful downloads' and links to other relevant internet sites under 'Useful links' as well as a list of selected references under the title of 'The Reference Guide', accessed via the 'Media and Students' link on the home page.

http://www.survivorscotland.org.uk/

This is a website developed by the Scottish Government as part of its National Strategy for Survivors of Childhood Sexual Abuse. The overarching aim of the site is to provide an 'information, education and networking' resource. Under the heading 'Research', a link to 'Research topics' provides a list of broad research areas, including: addiction, children, gender and violence, therapeutic issues and prevalence. Each research area is clickable and leads to a brief introduction followed by a list of links to pdf format examples of research on that topic.

http://www.broken-rainbow.org.uk/

Website of Broken Rainbow LGBT Domestic Violence (UK), a registered charity set up in 2002 with the objective of relieving the distress and suffering caused to lesbians, gay men, bisexual and transgender ('LGBT') people by domestic violence and abuse, through diverse mechanisms including: raising awareness, both inside the LGBT community and elsewhere; offering advice, support and referral services to LGBT people experiencing homophobic, transphobic and same sex domestic violence; offering information, advice and training to those responsible for domestic violence policy or involved with the survivors and perpetrators of domestic violence; running the National LGBT Domestic Violence helpline (in partnership with London Lesbian and Gay Switchboard). The site provides a set of frequently asked questions, available in a range of languages, and links to relevant organisations and research.

http://www.womenssupportproject.co.uk/

Website of the Glasgow-based Women's Support Project, part-funded by Glasgow City Council. The Project provides a telephone support and information service to people that have been affected by gender-based violence, with priority given to support for women whose children have been sexually abused, or where there is a risk of abuse. They also provide training and run public awareness raising events. The Project also runs a library service, through which hard copies of materials can be accessed. The website provides online access to a range of downloadable materials related to child sexual abuse and commercial sexual exploitation, whilst the Project's two resource lists provide bibliographies for these topic areas with citation information and brief summaries. The website also provides a comprehensive set of links to other services and websites that support people with the difficulties experienced due to the violence and abuse. 
http://www.edfwomen.org.uk/abuse.htm

Website produced by the UK Disability Forum for European Affairs' Women's Committee for use by disabled women, their friends and supporters to help to tackle a wide range of abuse experienced by disabled women. Information is provided on getting help with abuse in a variety of different contexts, with telephone numbers for and links to relevant organisations. Details of and links to helplines and support organisations are provided under the heading 'Resources for fighting abuse'.

\section{Harm and abuse prevention - policies, practices and resources}

http://www.dh.gov.uk/en/SocialCare/Deliveringadultsocialcare/Vulnerableadults/DH_261

This is part of the website of the Department of Health, a government department that provides strategic leadership to the NHS and social care organisations in England and is responsible, where national leadership or co-ordination is required, for the UK-wide response to public health issues. This page relates specifically to the care of vulnerable adults and contains links to different government policies and initiatives, related research, and other relevant information. From here it is possible to access, amongst other things: the 'No Secrets' guidance to local authorities together with findings from an analysis of local codes of practice; brief information on and links to documents detailing the Protection of Vulnerable Adults (PoVA) Scheme, research on referrals to the scheme, and details of the new Vetting and Barring Scheme (VBS); and research on abuse and neglect of older people.

http://www.dh.gov.uk/en/Consultations/Closedconsultations/DH_089098

This site provides access to pdf format documents that form part of the Department of Health's consultation on the review of the 'No Secrets' guidance. This guidance, issued to local authorities in England and Wales in 2000 under section 7 of the Local Authority Social Services Act 1970, created a statutory framework for a multi-agency response to the risk of harm or abuse. The consultation was launched on 16 October 2008 and closed on 31 January 2009. The response to the consultation was published on 17 July 2009 and can be accessed by following the 'Responses to consultations' link on the left-hand side of the webpage.

http://www.isa-gov.org.uk/default.aspx?page $=0$

This is the website of the Independent Safeguarding Authority (ISA), a non-departmental public body created under the Safeguarding Vulnerable Groups Act 2006 and charged with administering the new Vetting and Barring Scheme (VBS) across England, Wales and Northern Ireland. The role of the ISA is to work in conjunction with the Criminal Records Bureau (CRB) to assess the suitability of those who wish to work or volunteer with children and vulnerable adults in England, Wales and Northern Ireland, and to grant applicants ISA registration or to place them on a Barred list and inform their current employers. ISA registrations are reviewed whenever additional information becomes available. The site includes a 'Resource Library' that contains a glossary, links to relevant legislation, pdf format ISA Fact Sheets and Newsletters and documents relating to the ISA decision-making process, and FAQs. 
http://www.nspcc.org.uk/Inform/informhub_wda49931.html

This link accesses a specialised online child protection resource provided as part of the website of the National Society for the Prevention of Cruelty to Children (NSPCC), a charity that operates community-based services in England, Wales, Northern Ireland and the Channel Islands, together with the ChildLine telephone helpline and website available to younger people across the UK. The resources have been produced by, or in collaboration with the NSPCC, and, where appropriate, many are available to download in pdf format. They are designed for a range of different audiences, from children and parents to professionals and policy makers. Various different formats are represented, from research reports to toolkits to learning resources, and the materials cover subject areas such as bullying, child protection in sport and in training, child sexual abuse and domestic violence. 